\title{
Theoretical Aspect of Crystallization Temperature at Maximum Crystal Growth Rate
}

\author{
Norimasa OKUI \\ Department of Organic and Polymeric Materials, Tokyo Institute \\ of Technology, Ookayama, Meguro-ku, Tokyo 152, Japan
}

(Received April 24, 1987)

\begin{abstract}
The ratio of the temperature at which the nucleation rate or the crystal growth rate is maximum $\left(T_{\mathrm{cmax}}\right)$ to the melting temperature $\left(T_{\mathrm{m}}\right)$ was predicted theoretically as a function of two parameters: one is the ratio of the activation energy of migration through the nucleus-melt interface to the heat of fusion and the other is the ratio of the mean surface energy of a mole of repeat unit to the heat of fusion. The ratios of $T_{\mathrm{cmax}} / T_{\mathrm{m}}$ were evaluated from the above two parameters.
\end{abstract}

KEY WORDS Maximum / Rate / Crystallization Temperature / Melting Temperature / Nucleation / Crystal Growth / Activation Energy / Surface Energy / Heat of Fusion /

It has been well-known that a ratio of crystallization temperature at which crystallization rate is maximum $\left(T_{\mathrm{cmax}}\right)$ to melting temperature $\left(T_{\mathrm{m}}\right)$ is nearly a constant in most crystalline polymers ${ }^{30-32}$ in analogous with an empirical relationship between melting temperature and glass transition temperature $\left(T_{\mathrm{g}}\right) .^{33,34}$ In an extensive study on the relationship between $T_{\mathrm{m}}$ and $T_{\mathrm{g}}$ for 138 polymers, the ratio $T_{\mathrm{g}} / T_{\mathrm{m}}$ varies widely. ${ }^{35}$ There is no sharp division between the ratios of $T_{\mathrm{g}} / T_{\mathrm{m}}$ observed for symmetrical and that for unsymmetrical polymers: about $80 \%$ of polymers have values in the range $0.5-0.8$. The relation of $T_{\mathrm{cmax}} / T_{\mathrm{m}}$ is found not only in polymers but also in most metals ${ }^{36}$ and organic compounds. ${ }^{37,38}$

In a crystallization theory, ${ }^{1,36}$ the temperature dependence of homogeneous crystal nucleation rate and that of crystal growth rate from melt are generally described with the following exponential equation, where the crystal growth is based on the formation of a two-dimensional surface nucleus.

$$
\begin{gathered}
I=I_{0} \exp \left(-\Delta E / R T-\mathrm{K} 1 T_{\mathrm{m}}^{2} / R T(\Delta T)^{2}\right) \\
G=G_{0} \exp \left(-\Delta E / R T-\mathrm{K} 2 T_{\mathrm{m}} / R T \Delta T\right)
\end{gathered}
$$

where $I$ and $G$ are the rate of nucleation and the rate of crystal growth, respectively. $\Delta E$ is the energy of activation for migration through the nucleus-melt interface. $\mathrm{K} 1$ and $\mathrm{K} 2$ are a function of the free energy of the interface, the heat of fusion and the shape of nucleus or crystal. $\Delta T$ is the degree of supercooling $\left(T_{\mathrm{m}}-T\right)$, where $T$ is the crystallization temperature. $I_{0}$ and $G_{0}$ are constant and $R$ is the gas constant.

If $I_{0}, G_{0}, \Delta E$, and $K(\mathrm{~K} 1$ and $\mathrm{K} 2)$ are assumed to be independent of temperature, the crystallization temperature $\left(T_{\mathrm{cmax}}\right)$ at the maximum rate of nucleation $\left(I_{\max }\right)$ or that of crystal growth $\left(G_{\max }\right)$ is observed by equating to zero the derivative of eq 1 or 2 with respect to the temperature. The relations so found are for the maximum nucleation rate:

$$
\begin{gathered}
T_{\text {cmax }} / T_{\mathrm{m}}=\left(D^{2}-D+1\right) /\left(D^{2}+D+1\right) \\
I_{\max }=I_{0} \exp \left(-\mathrm{K} 1 T_{\mathrm{m}}^{2} / R\left(\Delta T_{\max }\right)^{3}\right)
\end{gathered}
$$




$$
\begin{gathered}
\text { where, } D=((B+1) /(B-1))^{1 / 3} \\
B=(1+\mathrm{K} 1 / \Delta E)^{1 / 2}
\end{gathered}
$$

for the maximum crystal growth

$$
\begin{gathered}
T_{\mathrm{cmax}} / T_{\mathrm{m}}=C /(1+C) \\
G_{\max }=G_{0} \exp \left(-\mathrm{K} 2 T_{\mathrm{m}} / R\left(\Delta T_{\max }\right)^{2}\right)
\end{gathered}
$$

where

$$
\begin{aligned}
& C=(1+\Delta E / \mathrm{K} 2)^{1 / 2} \\
& \Delta T_{\max }=T_{\mathrm{m}}-T_{\text {cmax }}
\end{aligned}
$$

The ratio of $T_{\text {cmax }} / T_{\mathrm{m}}$ depends only the ratio of $\Delta E / K$. Similar trials have been reported by Mandelkern et al ${ }^{31,32}$ for the maximum nucleation rate, but they could not get an equation as simple as the above. The greater the ratio of $\Delta E / K$ is the greater the ratio of $T_{\text {cmax }} / T_{\mathrm{m}}$ as seen in Figure 1, however, a large variation in $\Delta E / K$ in its high value regions causes little change in $T_{\text {cmax }} / T_{\mathrm{m}}$. In fact, the values of $\Delta E / K$ lie in about $10-40$ for most polymers (see in Table I), and this results in the ratios of $T_{\text {cmax }} / T_{\mathrm{m}}$ changing from 0.77 to 0.86 for the crystal growth and from 0.58 to 0.7 for the nucleation. The minimum values in $D$ and $C$ are 1 when the activation energy $\Delta E$ is zero, that is, the minimum ratios of $T_{\text {cmax }} / T_{\mathrm{m}}$ for the homogeneous nucleation and the crystal growth yield $1 / 3$ and $1 / 2$, respectively.

Here, the shape of the nucleus and the mode of the nucleation are assumed to be, respectively, a lamellar rhombohedron and a monomolecular surface nucleation on a flat substrate in a chain folding crystallization. ${ }^{1}$ Now, $\mathrm{K} 1$ and $\mathrm{K} 2$ are:

$$
\begin{aligned}
& \mathrm{K} 1=32 \sigma_{\mathrm{e}} \sigma_{\mathrm{u}}^{2} / \Delta H_{\mathrm{m}}^{2} \\
& \mathrm{~K} 2=4 \mathrm{~b}_{0} \sigma_{\mathrm{e}} \sigma_{\mathrm{u}} / \Delta H_{\mathrm{m}}
\end{aligned}
$$

where $\sigma_{\mathrm{u}}$ and $\sigma_{\mathrm{e}}$ are the lateral and the endsurface free energies, respectively. $b_{0}$ is the thickness of the depositing growth layer, $\Delta H_{\mathrm{m}}$ is the heat of fusion. Then, the ratios of $\Delta E / \mathrm{K} 1$ and $\Delta E / \mathrm{K} 2$ yield:

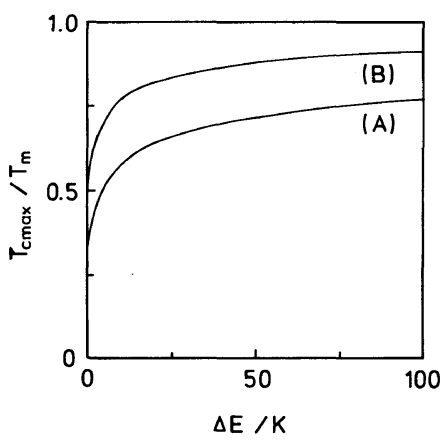

Figure 1. Ratio of maximum crystallization temperature to melting temperature for nucleation (A) and crystal growth (B) as a function of ratio of the activation energy for transport to the nucleation parameter.

$$
\begin{gathered}
\Delta E / \mathrm{K} 1=(1 / 32)\left(\Delta E / \Delta H_{\mathrm{m}}\right)\left(\bar{\sigma} / \Delta H_{\mathrm{m}}\right)^{-3} \\
\bar{\sigma}=\left(\sigma_{\mathrm{e}} \sigma_{\mathrm{u}}^{2}\right)^{1 / 3} \\
\Delta E / \mathrm{K} 2=(1 / 4)\left(\Delta E / \Delta H_{\mathrm{m}}\right)\left(\bar{\sigma} / \Delta H_{\mathrm{m}}\right)^{-2} \\
\bar{\sigma}=\left(b_{0} \sigma_{\mathrm{e}} \sigma_{\mathrm{u}}\right)^{1 / 2} \\
\alpha=\bar{\sigma} / \Delta H_{\mathrm{m}} \\
\beta=\Delta E / \Delta H_{\mathrm{m}}
\end{gathered}
$$

where $\bar{\sigma}$ is the mean surface energy of a mole of repeat unit.

Here, it is very interesting to note that the ratio of $\bar{\sigma}$ to $\Delta H_{\mathrm{m}}$ (hereafter, this ratio is denoted $\alpha$ ) is generally found to be constant for a given type of crystalline materials. For example, the value of $\alpha$ is fairly constant in most metals. ${ }^{36}$ In addition, $\Delta E / \Delta H_{\mathrm{m}}$ is also found to be a constant in most of metals. ${ }^{39,40}$ Then, $T_{\text {cmax }} / T_{\mathrm{m}}$ will yield almost constant. However, main problem in relating the theory to experiments lies in evaluating $\bar{\sigma}$ and $\Delta E$ quantities. The values of $\Delta E$ may be closely related to the activation energy for the selfdiffusion $\left(\Delta E_{\mathrm{D}}\right)$ of chain molecules, however, the values of $\bar{\sigma}$ can not be measured in any other way.

\section{Ratio of $\Delta E / \Delta H_{\mathrm{m}}(\beta)$}

The activation energy for transport of chain segments to the crystal-melt interface, $\Delta E$, can be expressed in terms of the equation either 
Table I. Ratio of maximum crystallization temperature to melting temperature and the characteristic parameters

\begin{tabular}{|c|c|c|c|c|c|c|}
\hline \multirow{2}{*}{ Materials } & \multicolumn{2}{|c|}{$T_{\mathrm{c} \max } / T_{\mathrm{m}}$} & \multirow{2}{*}{$\bar{\sigma} / \Delta H_{\mathrm{m}}^{\mathrm{a}}$} & \multirow{2}{*}{$\Delta E / \Delta H_{\mathrm{m}}^{\mathrm{b}}$} & \multirow{2}{*}{$\Delta E / \mathrm{K} 2^{\mathrm{c}}$} & \multirow{2}{*}{ Ref. $^{d}$} \\
\hline & Obsd & Calcd & & & & \\
\hline PCITFE & & $0.82-0.83$ & $0.36-0.38$ & 11.83 & $20.5-22.8$ & 1,2 \\
\hline $\mathrm{PE}$ & & $0.76-0.78$ & $0.34-0.37$ & 5.14 & $9.4-11.1$ & $1,2,3$ \\
\hline iso-PP & & 0.81 & 0.29 & 5.71 & 17 & 4 \\
\hline syd-PP & & 0.75 & 0.43 & $(5.71)$ & 7.7 & 5 \\
\hline PB-1 & & $0.81-0.82$ & $0.29-0.30$ & 6.24 & $17.3-18.5$ & 9 \\
\hline PS & $0.87-0.89$ & 0.86 & $0.25-0.26$ & 9.52 & $35.2-38.1$ & $6-9$ \\
\hline $\mathrm{PVF}_{2}$ & & 0.75 & 0.41 & $(5.5)$ & 8.2 & 10 \\
\hline PTMPS & $0.78-0.83$ & $0.77-0.82$ & $0.24-0.35$ & 4.81 & $9.8-20.9$ & 11,12 \\
\hline PET & $0.79-0.86$ & $0.81-0.92$ & $0.10-0.29$ & $(5.5)$ & $16.3-138$ & $13-15$ \\
\hline POM & 0.79 & 0.82 & 0.26 & 5.44 & 20.1 & 16 \\
\hline PEO & & $0.76-0.79$ & $0.22-0.26$ & 2.39 & $8.8-12.3$ & $17-19$ \\
\hline PPO & $0.82-0.88$ & $0.82-0.85$ & $0.20-0.25$ & 4.85 & $19.4-30.3$ & 20,21 \\
\hline PESu & 0.86 & 0.85 & 0.21 & $(5.5)$ & 31.2 & 22 \\
\hline PPhAd & 0.85 & 0.86 & 0.19 & $(5.5)$ & 38.1 & 23 \\
\hline PDMS & 0.82 & 0.82 & 0.14 & 1.65 & 21 & 24 \\
\hline N6 & $0.81-0.82$ & $0.77-0.82$ & $0.18-0.25$ & 2.65 & $10.6-20.4$ & $25-28$ \\
\hline N56 & 0.85 & 0.80 & 0.16 & 1.53 & 14.9 & 29 \\
\hline N66 & 0.76 & 0.86 & 0.1 & 1.2 & 38 & 26 \\
\hline $\mathrm{N} 12$ & & 0.76 & 0.18 & $(1.2)$ & 9.3 & 28 \\
\hline N96 & 0.87 & 0.82 & 0.12 & 1.13 & 19.6 & 29 \\
\hline
\end{tabular}

${ }^{a}$ Values analyzed from data existed in the literature (d). ${ }^{b}$ Values based on Mandelkern's results. ${ }^{41}$ Numbers in brackets refer to values assumed according to eq 19 or $20 .{ }^{c}$ Values calculated from eq 15 using a set of data a and b. PCITFE, poly(chlorotrifluoroethylene); PS, poly(styrene); PE, poly(ethylene); iso-PP, isotactic-poly(propylene); syd-PP, syndiotactic-poly(propylene); $\mathrm{PB}-1$, poly(butene-1); $\mathrm{PVF}_{2}$, poly(vinylidene fluoride); PTMPS, poly(tetramethyl$p$-silphenylene siloxane); PET, poly(ethylene terephthalate); POM, poly(methylene oxide), PPO, poly(propylene oxide); PEO, poly(ethylene oxide); PESu, poly(ethylene succinate); PPhAd, poly(tetrachloro-bis-phenol adipate); PDMS, poly(dimethyl siloxane); N6, Nylon-6; N56, Nylon-56; N66, Nylon-66; N12, Nylon-12; N96, Nylon-96.

WLF or Arrhenius. In this study, however, $\Delta E$ is expressed by Arrhenius' equation, since the simplified expression is adequate for solving the differential equation of (1) and (2) respect to temperature. The crystal growth data for many polymers have been analyzed by Mandelkern et al. according to possible nucleation mechanism and they have estimated $\Delta E$ by assuming Arrhenius' equation. ${ }^{41}$ Those data plotted as a function of the heat of fusion show good linear relations, although data are scattered, as seen in Figure 2. In most of polymers without hydrogen bonding groups in the chemical structures,

$$
\Delta E / \Delta H_{\mathrm{m}}=5.5
$$

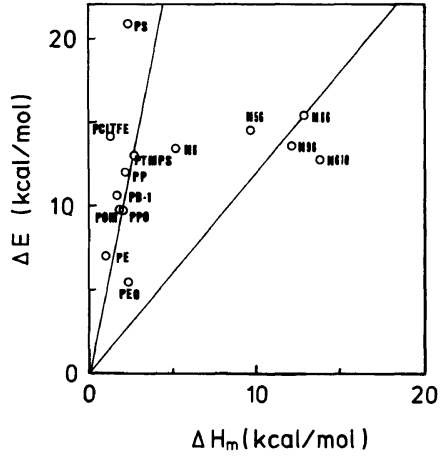

Figure 2. Relationship between the activation energy for transport and the heat of fusion in various polymers.

In polymers with hydrogen bonding groups, such as nylons, 


$$
\Delta E / \Delta H_{\mathrm{m}}=1.2
$$

Here, $\Delta E$ is compared with the activation energy for viscous flow or for self-diffusion of polymer chain that may related to the reputation mechanism. For example, $\Delta E$ can be regarded as being equal the activation energy for sliding diffusion of a molecule on the nucleus surface. ${ }^{59}$ In the chain folding mechanism for polymer crystallization, a part of a polymer molecule contacts a preexisting nucleus surface and subsequently some other parts of the molecule in question deposit adjacently on the same nucleus surface. Translational shift along the chain axis needs the self-diffusion energy to generate a crystalline packing finding a set of nearest lattice points. In fact, molecules can not jump directly into the lattice points from the liquid phase. Such diffusion energy must be associated with the reptation energy of polymer molecules. For example, the reptation energy is close to $5500 \mathrm{cal} / \mathrm{mol}$ for $n$-paraffins. ${ }^{42}$ This suggests that the $\Delta E / \Delta H_{\mathrm{m}}$ yields $c a .5 .6$ which is in satisfactory agreement with eq 19. In metals, $\Delta E_{\mathrm{D}}$ is available experimentally from self-diffusion study both in the melts and in the solids. The ratio of $\Delta E_{\mathrm{D}} /$ $\Delta H_{\mathrm{m}}$ in metals is also found to be fairly constant both for melts and solids. ${ }^{39,40}$ The relation between the activation energy for selfdiffusion and $\Delta H_{\mathrm{m}}$ has been established on the base of the idea that the activation energy for a vacancy mechanism of diffusion is equal numerically to the maximum change in the crystal internal energy. ${ }^{60}$ In other words, the ratio of $\Delta E_{\mathrm{D}} / \Delta H_{\mathrm{m}}$ equals the ratio of the activation volumes of fusion and diffusion. ${ }^{61}$ Also, it is interesting to note that the ratio of the activation energy of vaporization $\left(\Delta E_{\text {vap }}\right)$ to that of viscous flow $\left(\Delta E_{\mathrm{vis}}\right)$ has been found to be a constant in metals and organic compounds. ${ }^{43}$ These three thermodynamic energies are supposed to be a function of cohesion energy, hence $\Delta E_{\mathrm{D}} / \Delta H_{\mathrm{m}}$ and $\Delta E_{\mathrm{vis}} / \Delta E_{\mathrm{vap}}$ will be a constant in all materials.
In fact, the ratio of the molar cohesion energy in polymer melts to the heat of fusion has been reported to be almost constant. ${ }^{44}$

\section{Ratio of $\bar{\sigma} / \Delta H_{\mathrm{m}}(\alpha)$}

An empirical relationship between $\bar{\sigma}$ and $\Delta H_{\mathrm{m}}$ in most of metals and molecular liquids has been noted by Turnbull. ${ }^{36}$ The homogeneous nucleation experiments of Turnbull yield the value of $\alpha$ to be roughly constant for a given type of materials. In the case of metals, the $\alpha$ is $c a .0 .45$ and for semimetals, water and organic compounds the raio is $c a$. 0.32 . The value of $\alpha$ for metals has been predicted to be $0.46-0.48$ by theoretical calculation on the basis of nearest neighbor cluster approximation. ${ }^{45}$ Since a molecule in the surface may be regarded as partly in the liquid, one might expect $\sigma$ to be of the order of one-half the $\Delta H_{\mathrm{m}}$. It has been also found that analogous relations exist between liquid-vapor interfacial energies and the heat of vaporization. ${ }^{46}$

The $\alpha$ for polymers can be calculated directly from crystallization kinetic data of $K$.

For homogeneous nucleation data of $\mathrm{K} 1$,

$$
\alpha=\left(\mathrm{K} 1 / 32 \Delta H_{\mathrm{m}}\right)^{1 / 3}
$$

A few homogeneous nucleation data is available in the literature. For example, using the nucleation data of PE obtained from small droplet experiments, ${ }^{47,48}$ the $\alpha$ was analyzed to be $0.31-0.32$.

From the crystal growth data of K2,

$$
\alpha=\left(\mathrm{K} 2 / 4 \Delta H_{\mathrm{m}}\right)^{1 / 2}
$$

In contrast with the homogeneous nucleation data, numbers of data are available for polymer crystal growth as listed in Table I, which values were analyzed by this work. It is also divided into two polymer groups in analogy with the raio of $\Delta E / \Delta H_{\mathrm{m}}$ as discussed above. That is, in most of polymers without hydrogen bonding groups,

$$
\alpha=0.2-0.4
$$


For polymers with hydrogen bonding groups, such as nylons,

$$
\alpha=0.1-0.2
$$

The average values of $\alpha$ for polymers with and without hydrogen bonding groups are 0.15 and 0.3 , respectively.

Also, there is interesting empirical relationship between $\sigma_{\mathrm{u}}$ and $\Delta H_{\mathrm{m}}$ reported by Hoffman et al. ${ }^{49}: \sigma_{\mathrm{u}} / \Delta H_{\mathrm{m}} \fallingdotseq 0.1$. Using this relationship and the values of $\alpha$ for the homogeneous nucleation and those for the crystal growth, $\sigma_{\mathrm{e}} / \Delta H_{\mathrm{m}}$ can be estimated. For example, $\sigma_{\mathrm{e}} / \Delta H_{\mathrm{m}}$ for PE is $c a .3-3.3$ for the nucleation and $c a$. $1.2-1.4$ for the crystal growth. The fold surface energy, $q$, has been calculated for PE on the base of molecular potential energy of gauche conformation. The energy of $q$ is $2500 \mathrm{cal} \mathrm{mol}^{-1}$ when the gauche energy is assumed to be $500 \mathrm{cal} \mathrm{mol}^{-150}$ or $4000 \mathrm{cal} \mathrm{mol}^{-1}$ when the gauche energy is assumed to be $800 \mathrm{cal} \mathrm{mol}^{-1} .{ }^{51}$ This suggests that the ratio of $\sigma_{\mathrm{e}} / \Delta H_{\mathrm{m}}$ is 2.55 or 4.1 , respectively, for the former or the latter gauche energy. The value of $\sigma_{\mathrm{e}} / \Delta H_{\mathrm{m}}$ estimated from the homogeneous nucleation is in satisfactory agreement with the theoretically predicted value. On the other hand, the value of $\sigma_{\mathrm{e}} / \Delta H_{\mathrm{m}}$ for the crystal growth is smaller by about a factor of $1 / 2$ from that of the homogeneous nucleation. In general, the surface energy deduced from the homogeneous nucleation is greater than that from the crystal growth or from the crystal melting temperature as a function of the crystallite thickness. This may cause the discrepancy between the above $\sigma_{\mathrm{e}} / \Delta H_{\mathrm{m}}$, although, an origin of the discrepancy is not clear.

\section{Ratio of $T_{\mathrm{cmax}} / T_{\mathrm{m}}$}

Experimental results of $T_{\mathrm{cmax}} / T_{\mathrm{m}}$ that exist in the literature for many polymers have been summarized by Godovski, ${ }^{30}$ where $T_{\text {cmax }} / T_{\mathrm{m}}$ lies almost between $0.8-0.9$. In the absence of experimental results of the maximum crystallization temperature for the other polymers, $T_{\text {cmax }} / T_{\mathrm{m}}$ can be evaluated from eq 3 or 7 . That is, $T_{\text {cmax }} / T_{\mathrm{m}}$ is only a function of $\Delta E / K$. And $\Delta K / K$ is a function of $\Delta E / \Delta H_{\mathrm{m}}$ and $\bar{\sigma} / \Delta H_{\mathrm{m}}$. If $\Delta E / \Delta H_{\mathrm{m}}$ and $\bar{\sigma} / \Delta H_{\mathrm{m}}$ are obtained by experiments or evaluated from theoretically, $T_{\text {cmax }} /$ $T_{\mathrm{m}}$ can be calculated from these two parameters. The values thus calculated are listed in Table I. For PCITFE, PE, iso-PP, and PEO, the rate of crystal growth is very rapid, so that the maximum crystal growth is difficult to attain by usual experimental method. However, the crystal growth can be simulated from experimental kinetic data. Such simulations have been made for $\mathrm{PE}$ and PCITFE $^{1,2}$ that $T_{\text {cmax }} / T_{\mathrm{m}}$ are, respectively, 0.872 and 0.875 which are somewhat larger than those from calculation made by this work as listed in Table I. An average value on $\Delta E / \mathrm{K} 2$ for all polymers in Table $\mathrm{I}$ is $c a$. 22. This yields that $T_{\text {cmax }} / T_{\mathrm{m}}$ is $c a .0 .83$ which fits very well with the average of experimental observations of 0.83 .

For nucleation data of PE crystals, $\alpha$ is $c a$. 0.31 as noted above. If $\Delta E / \Delta H_{\mathrm{m}}$ of PE in the nucleation process is the same order of the crystal growth: $\Delta E / \Delta H_{\mathrm{m}}=5-10, T_{\mathrm{cmax}} / T_{\mathrm{m}}$ is thus estimated to be $0.52-0.58$. This estimation suggests that the maximum nucleation rate will occur at temperature about -30 $-55^{\circ} \mathrm{C}$. In fact, $\mathrm{PE}$ is well-known as an unquenchable polymer and an amorphous $\mathrm{PE}$ can only be achieved by an ultra-high speed quenching method from the molten state. ${ }^{52}$ Such amorphous PE is nucleated at near $-100^{\circ} \mathrm{C}^{52}$ So, the nucleation temperature evaluated above in the vicinity of -30 $-50^{\circ} \mathrm{C}$ at the maximum nucleation rate may be a reasonable temperature.

It would be appeared that the smaller the surface energy yields the higher the maximum crystallization temperature $\left(T_{\text {cmax }}\right)$ according to eq 3 or 7 . In fact, aromatic hydrocarbons, such as 1,3,5-tri- $\alpha$-naphthyl benzene, ${ }^{53}$ 1,2diphenyl benzene, ${ }^{54}$ benzophenone, ${ }^{55}$ and betol, ${ }^{56}$ show that the ratio of $T_{\mathrm{cmax}} / T_{\mathrm{m}}$ for the crystal growth is $c a$. 0.95 , where the $\alpha$ is $c a$. $0.05 .{ }^{40}$ On the other hand, $T_{\mathrm{cmax}} / T_{\mathrm{m}}$ for the 
homogeneous nucleation of betol shows $c a$. 0.8 , where the $\alpha$ is $c a$. 0.11 . In the homogeneous nucleation of normal alkanes, $\alpha$ increases from 0.07 to 0.28 with a decrease in chain length. ${ }^{5,58}$ This may suggest that $T_{\text {cmax }} / T_{\mathrm{m}}$ changes from 0.84 to $0.56 .^{40}$ Further discussion in many other crystalline materials, such as metals, molecular liquids, organic compounds and inorganic materials, will be reported elsewhere. ${ }^{40}$ That $\alpha$ and $\beta$ have roughly constant values for a given type of materials is an important deduction, and by a process of feed-back the existence of the relation between the ratio of $T_{\mathrm{cmax}} / T_{\mathrm{m}}$ and the above two characteristic parameters provides one of the more important supports for the present work.

\section{CONCLUSION}

The ratio of the temperature at which the nucleation rate is maximum $\left(T_{\mathrm{cmax}}\right)$ to the melting temperature $\left(T_{\mathrm{m}}\right)$ was formulated as $T_{\text {cmax }} / T_{\mathrm{m}}=\left(D^{2}-D+1\right) /\left(D^{2}+D+1\right)$, where $D$ is a function of the ratio of $\Delta E / K . \Delta E$ is the activation energy of migration through the nucleus-melt interface and $K$ is the nucleation parameter associated with the surface energy and the heat of fusion $\left(\Delta H_{\mathrm{m}}\right)$. The ratio of the temperature at which the crystal growth rate is maximum $\left(T_{\text {cmax }}\right)$ to the melting temperature ( $\left.T_{\mathrm{m}}\right)$ was also formulated as $T_{\text {cmax }} / T_{\mathrm{m}}=$ $C /(1+C)$, where $C$ is a function of $\Delta E / K$. The ratio of $\Delta E / K$ is a function of the ratios of $\Delta E / \Delta H_{\mathrm{m}}$ and $\bar{\sigma} / \Delta H_{\mathrm{m}}$, where $\bar{\sigma}$ is the mean surface energy of a mole of repeat unit. $\bar{\sigma} / \Delta H_{\mathrm{m}}$ varies between $0.1-0.4$ and $\Delta E / \Delta H_{\mathrm{m}}$ is almost constant in most polymers. The ratios of $T_{\mathrm{cmax}} / T_{\mathrm{m}}$ were evaluated from the ratios of $\bar{\sigma} / \Delta H_{\mathrm{m}}$ and $\Delta E / \Delta H_{\mathrm{m}}$.

\section{REFERENCES}

1. J. D. Hoffman and J. J. Weeks, J. Chem. Phys., 37, 1723 (1962).

2. J. I. Lauritzen and J. D. Hoffman, J. Appl. Phys., 44, 4340 (1973).
3. W. M. Leung, R. St. J. Manley, and A. R. Panaras, Macromolecules, 18, 760 (1985).

4. Y. K. Godovskii and G. L. Slonimskii, Polym. Sci. USSR, 11, 1461 (1969).

5. R. L. Miller and E. G. Seeley, J. Polym. Sci., Polym. Phys. Ed., 20, 2297 (1982).

6. H. D. Keith and F. J. Padden, J. Appl. Phys., 35, 1286 (1964).

7. J. Boon, G. Challa, and D. W. Van Krevelen, $J$. Polym. Sci., A-2, 6, 1791 (1986).

8. J. Boon and J. M. Azcue, J. Polym. Sci., A-2, 6, 885 (1968).

9. T. Suzuki and A. J. Kovacs, Polym. J., 1, 82 (1970).

10. R. L. Miller, "Flow-Induced Crystallization in Polymer Systems," R. L. Miller, Ed., Gordon \& Breach Science, Publishers, London, 1977, p 31.

11. J. H. Magill, J. Appl. Phys., 35, 3249 (1964).

12. J. H. Magill, J. Polym. Sci., A-2, 5, 89 (1967).

13. V. G. Baranov, A. V. Kenarov, and T. I. Volkov, J. Polym. Sci., C, 30, 271 (1970).

14. F. Van Antwerpen and D. W. Van Krevelen, $J$. Polym. Sci., Polym. Phys. Ed., 10, 2423 (1972).

15. J. D. Muzzy, D. G. Bright, and G. H. Hoyos, Polym. Eng. Sci., 18, 437 (1978).

16. M. Inoue and M. Takayanagi, J. Polym. Sci., 47, 498 (1960).

17. J. Q. R. Maclaine and C. Booth, Polymer, 16, 191 (1975).

18. A. J. Kovacs, C. Straupe, and A. Gonthier, J. Polym. Sci., Polym. Symp., 59, 31 (1977).

19. S. Cimmino, R. Gerco, E. Martusselli, and C. Silvestre, Makromolecules, 180, 219 (1979).

20. J. H. Magill, Macromolecules, 86, 283 (1965).

21. M. A. Kennedy, G. R. Brown, and L. E. St-Pierre, Polym. Compost., 5, 307 (1984).

22. M. Takayanagi and T. Yanashita, J. Polym. Sci., 22, 552 (1956).

23. H. Berghmans, E. Lanza, and G. Smets, J. Polym. Sci., Polym. Phys. Ed., 11, 87 (1973).

24. Y. K. Godovskii, V. Y. Levin, and G. L. Slonimskii, Polym. Sci. USSR, 11, 2778 (1969).

25. B. B. Burnett and W. F. McDevit, J. Appl. Phys., 28, 1101 (1957).

26. J. H. Magill, Polymer, 6, 367 (1965).

27. C. J. Ong and F. P. Price, J. Polym. Sci., Polym. Symp., 63, 59 (1978).

28. H. Mitomo and H. Tonami, Kobunshi Kagaku, 28, 630 (1971).

29. J. H. Magill, J. Polym. Sci., A, 3, 1195 (1965).

30. Y. K. Godovskii, Polym. Sci. USSR, 11, 2423 (1969).

31. L. Mandelkern, F. A. Quinn, and P. J. Flory, J. Appl. Phys., 25, 830 (1954).

32. L. Mandelkern, J. Appl. Phys., 26, 443 (1955)

33. R. F. Boyer, J. Appl. Phys., 25, 825 (1954).

34. R. G. Beaman, J. Polym. Sci., 9, 470 (1953).

35. W. A. Lee and G. J. Knight, Br. Polym. J., 2, 73 (1970). 
36. D. Turnbull, J. Appl. Phys., 21, 1022 (1950).

37. D. G. Thomas and L. A. K. Staveley, J. Chem. Soc., 4569 (1952).

38. H. J. Nordwall and L. A. K. Staveley, J. Chem. Soc., 224 (1954).

39. P. G. Shewmon, "Diffusion in Solids," MacGrawHill, New York, N. Y., 1963, p 64.

40. N. Okui, to be published.

41. L. Mandelkern, N. L. Jain, and H. Kim, J. Polym. Sci., A-2, 6, 165 (1968).

42. J. H. Flynn, Polymer, 23, 1325 (1982).

43. R. H. Ewell and H. Erying, J. Chem. Phys., 5, 726 (1937).

44. V. P. Privalko, Polym. J., 10, 607 (1978).

45. F. Spaepen, Acta Meta., 23, 729 (1975).

46. A. S. Skapski, J. Chem. Phys., 16, 386 (1948).

47. R. L. Cornia, F. P. Price, and D. Turnbull, J. Chem. Phys., 37, 1333 (1962).

48. F. Gornick, G. S. Ross, and L. J. Frolen, J. Polym. Sci., C, 18, 79 (1967).

49. J. D. Hoffman, Makromolecules, 18, 772 (1985).
50. P. J. Flory, C. A. J. Hoeve, and Cifferri, J. Polym. Sci., 34, 337 (1959).

51. F. C. Frank and M. Tosi, Proc. R. Soc., London, Ser. $A, 263,323$ (1961).

52. J. B. Jones, S. Barenberg, and P. H. Geil, Polymer, 20, 903 (1979).

53. J. H. Magill and D. J. Plazek, J. Chem. Phys., 46, 3757 (1967).

54. R. J. Greet, J. Cryst. Growth, 1, 195 (1967).

55. D. E. Ovsienko and G. A. Alfintsev, "Crystals, Growth and Properties," Vol. 2, Springer-Verlag, New York, N. Y., 1980, p 119.

56. G. S. Zhdanov, "Crystal Physics," Academic Press, New York, N. Y., 1965, p 365.

57. M. J. Oliver and P. D. Calvert, J. Cryst. Growth, 30, 343 (1975).

58. D. R. Uhlmann, G. Kritchevsky, R. Straff, and G. Scherer, J. Chem. Phys., 62, 4896 (1975).

59. M. Hikosaka, Polymer, 28, 1257 (1987).

60. P. P. Kuzumenko, Ukr. Fiz. Ah., 17, 569 (1972).

61. P. P. Kuzumenko, Metallofizika, No. 39, 111 (1972). 